\title{
Recent advances on the synthetic applications of the dithioacetal functionality
}

\author{
Tien-Yau Luh a,b,* \\ a Department of Chemistry, National Taiwan University, Taipei 106, Taiwan, ROC \\ b Institute of Chemistry, Academia Sinica, Nankang, Taipei 115, Taiwan, ROC \\ Received 9 September 2001; received in revised form 27 November 2001; accepted 29 November 2001 \\ Dedicated to Professor Robert J.H. Corriu, Professor Jay K. Kochi, Makoto Kumada, and Akio Yamamoto for their pioneering \\ contributions to the cross coupling reactions
}

\begin{abstract}
Recent advances on the synthetic applications of the dithioacetal functionality are briefly reviewed. Nickel-catalyzed silylolefination reaction has led to the synthesis of a range of silyl-substituted olefins for optoelectronic interests. The reactions of propargylic dithioacetals with organocopper or lithium reagent followed by treatment with electrophiles yield the corresponding sulfur-substituted allenes. Further cross coupling with the Grignard reagent in the presence of a nickel catalyst affords highly substituted allenes. Acid-catalyzed cyclization of the sulfur-substituted allenyl alcohols furnishes a useful route for the synthesis of oligoaryls having highly substituted furan or pyrrole moieties. C) 2002 Elsevier Science B.V. All rights reserved.
\end{abstract}

Keywords: Dithioacetal; Cross coupling; Annulation; Zwitterion synthon; Silylolefination

\section{Introduction}

The discovery of the cross coupling reactions have led to a great leap forward in organic synthesis [1]. Carbon-carbon bond, as well as carbon-heteroatom bond, involving a $\mathrm{C}_{\mathrm{sp}^{2}}$ center can easily be formed by these protocols. An extension of this reaction to convert a carbon-sulfur bond into a carbon-carbon bond was achieved in 1979 by Takei and Wenkert (Eq. (1) and (2)) [2]. Whereas the benzylic thioether substrate is quite unreactive under these conditions [3], the discovery of the nickel-catalyzed cross coupling reaction of benzylic or allylic dithioacetals with Grignard reagents has paved a new route for the olefination of a carbonyl equivalent [4]. Representative examples are shown in Scheme 1 [4-8]. In these reactions, one of the carbon-sulfur bonds is replaced by a carbon-carbon bond, and the second carbon-sulfur bond undergoes formal

\footnotetext{
* Tel.: + 886-2-2789-8500; fax: + 886-2-2364-4971.

E-mail address: tyluh@chem.sinica.edu.tw (T.-Y. Luh).
}

elimination to give an alkene. The reaction is particularly useful for the synthesis of vinylsilanes [5]. When the cyclopropyl Grignard reagent is employed in these cross coupling reactions, the corresponding butadienes are obtained in good yield [6]. Accordingly, the dithioacetal functionality can be considered as a germinal dication synthon. Indeed, the reaction of a dimetallic species with benzylic dithioacetals furnishes an alternative procedure for the olefination of dithioacetals [7]. The key to the success of this reaction relies on the involvement of a chelation intermediate 1 , which activates the second carbon-sulfur bond [8].

$$
\begin{gathered}
\mathrm{SPh} \frac{\mathrm{PhMgBr}}{\mathrm{NiCl}_{2}\left(\mathrm{PPh}_{3}\right)_{2}}=\underbrace{\mathrm{Ph}} \\
\frac{\mathrm{BuMgBr}}{\mathrm{NiCl}_{2} \text { (dppe) }}
\end{gathered}
$$

This brief account summarizes our recent results based on this olefination reactions and related reactions on the synthetic applications of the dithioacetal functionality. 


\section{Silylolefination}

Organic conjugated chromophores can exhibit a variety of fascinating optoelectronic properties [9]. Introduction of a bulky substituent to the substrates has been occasionally employed to prevent aggregation of the molecules in an electronic device. In addition, the thermal stability of organic substrates plays a pivotal role on the lifetime of devices. It is noteworthy that the benzylic carbon-carbon bond is somewhat weaker than the silicon-carbon bond in the corresponding silicon analogues. Consequently, there has been an ever burgeon use of organosilicon compounds in the optoelectronic applications [10]. As shown in Scheme 1, the olefination of dithioacetals is particularly useful for the synthesis of vinylsilanes [5]. The substituent(s) on the silicon atom can readily be tuned, and organosilicon compounds of different structural variety can be conveniently synthesized. With this strategy in mind, we have achieved in synthesizing several vinylsilanes that exhibit interesting potential for electroluminescent applications.

Reaction of bisdithioacetal 2 with $\mathrm{Ph}_{2} \mathrm{MeSiCH}_{2} \mathrm{MgCl}$ in the presence of $3 \mathrm{~mol} \%$ of $\mathrm{NiCl}_{2}\left(\mathrm{PPh}_{3}\right)_{2}$ gives the corresponding bisolefination product $\mathbf{3}$ in $80 \%$ yield (Eq. (3)). It is interesting to note that 3 can serve as a hole-blocking material for a device constituted of ITO4-3- $\mathrm{Alq}_{3}-\mathrm{Mg}-\mathrm{Ag}[11]$.
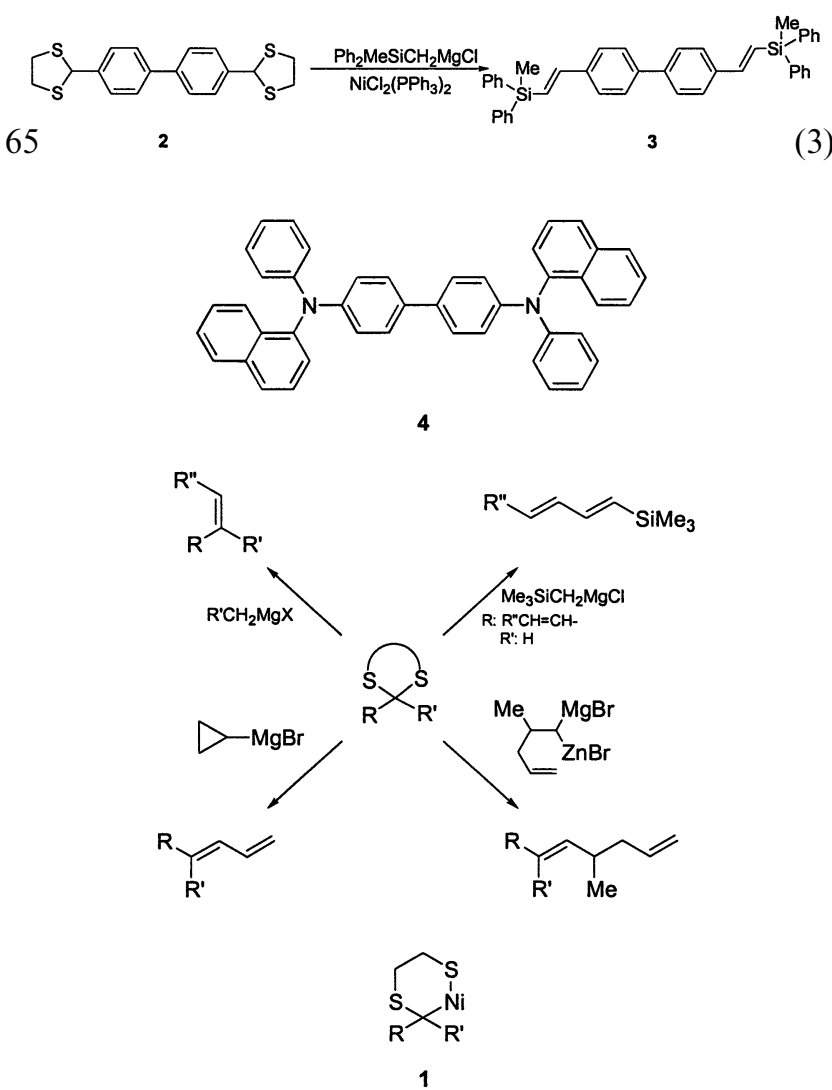

Scheme 1.
Alkoxysilyl-substituted styrene derivatives can be conveniently obtained from this silylolefination protocol. Bisvinylsilane 6 is synthesized from the corresponding bisdithioacetal 5 [12]. Base or TBAF-induced dimerization of $\mathbf{6}$ yields the corresponding siloxanetethered paracyclophane 7 (Eq. (4)) [13]. Treatment of 8 with base in the presence of $(\mathrm{EtO})_{4} \mathrm{Si}$ affords the corresponding sol gel $\mathbf{9}$ having divinylarene chromophore (Eq. (5)) [14].

The silicon-oxygen bond can readily be reduced to the corresponding silyl hydride [12]. Bis-silyl hydride $\mathbf{1 2}$ obtained from $\mathbf{1 0}$ serves as a powerful arsenal for the synthesis of a variety of alternating copolymers $\mathbf{1 3}$, containing the silylene moiety as the insulating spacer between chromophores (Eq. (6)) [12]. This strategy has provided a useful procedure for the synthesis of a variety of copolymers, having alternating donor and acceptor chromophores separated by
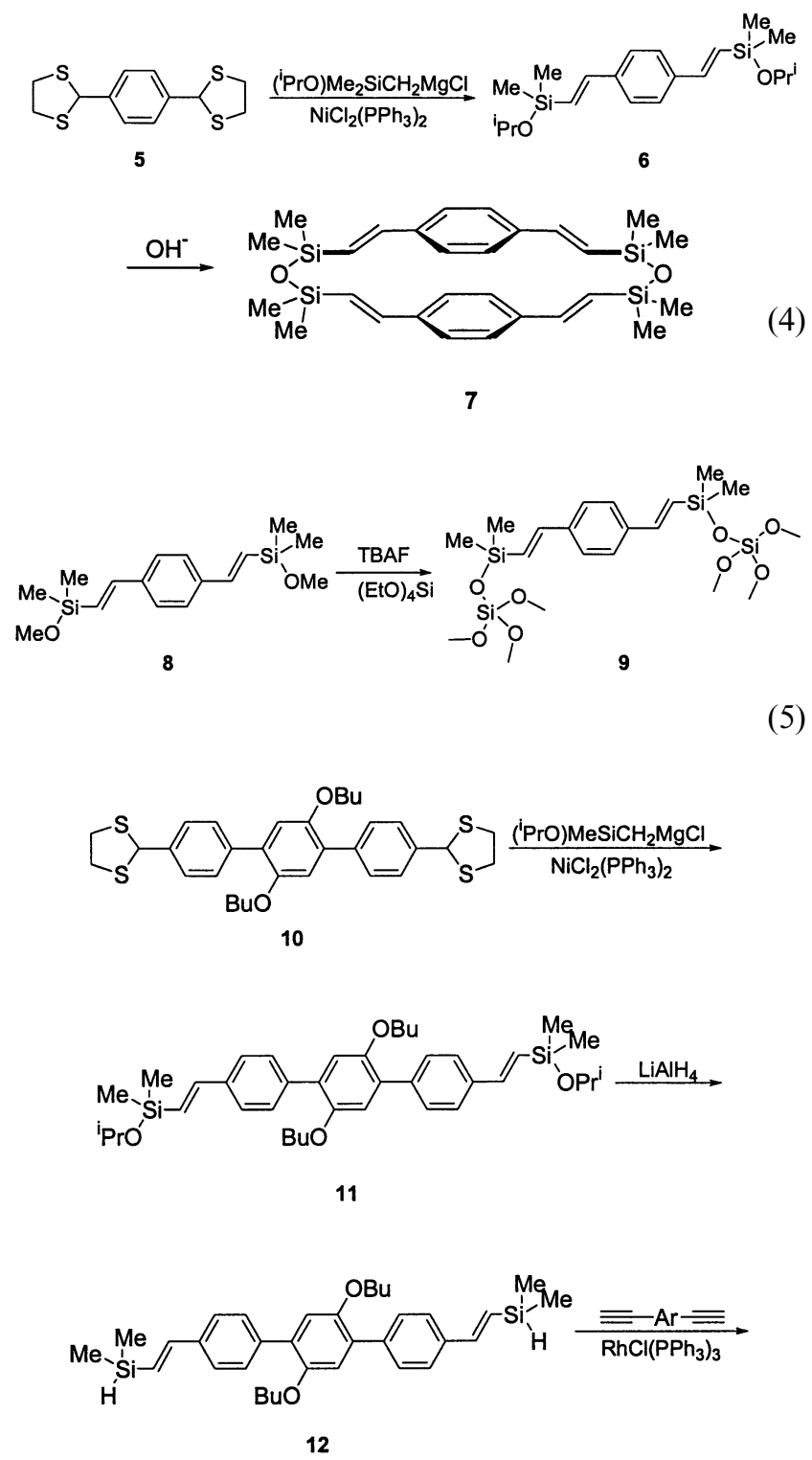


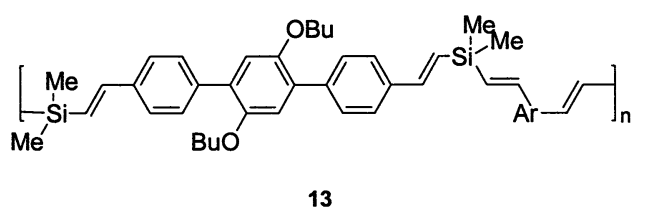

the silicon spacer. The photophysical properties and the optoelectronic applications of $\mathbf{1 3}$ have been briefly explored [15].

The silyl-substituted monomeric light emitting material $\mathbf{1 4}$ is synthesized in a similar manner. Bright blue emission is obtained from a device containing $\mathbf{1 4}$ as a dopant [16].

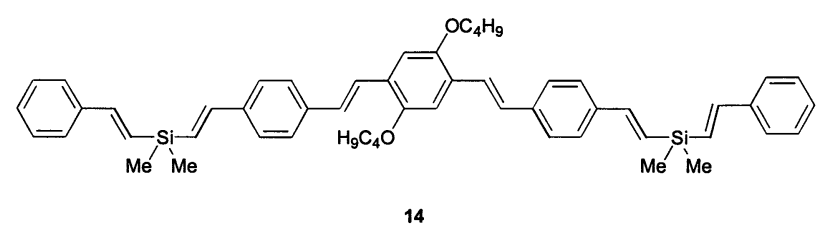

\section{Dithioacetal as a zwitterion synthon}

The electronegativities of carbon and sulfur atoms are similar. These intriguing properties lead to the rich chemistry of organosulfur compounds. The reactivity of the carbon-sulfur bond towards a nucleophile can also be altered depending on the reaction conditions. In other words, either a sulfide anion or a carbanion can serve as a leaving group in these reactions. Relatively speaking, nucleophilic substitution reactions involving the carbanionic leaving group is rare, unless this anionic species is somewhat stabilized $[17,18]$. The dithioacetal functionality turns out to be an ideal substrate for this purpose because the carbanion moiety generated by nucleophilic attack at one of the two sulfur atoms will be stabilized by the remaining sulfur group. Indeed, treatment of butyl lithium with a benzylic dithioacetal 15 followed by protonation yields the corresponding thioether 16 (Eq. (7)) [18]. An extension of this reaction to the propargylic system has led to the discovery of several interesting transformations.

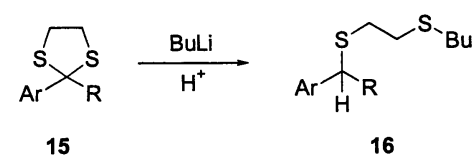

\subsection{Synthesis of substituted allenes}

Treatment of propargylic dithioacetal 17 with an organocopper reagent followed by quenching with an electrophile affords either sulfur-substituted allene $\mathbf{2 0}$ or alkyne 21, depending on the nature of the electrophile
[19]. In the presence of a proton source, allene is obtained exclusively in $73-95 \%$ yield. (20, E = H, Eq. (8)). In a similar manner, allenyl silanes and stannanes can be prepared (20, $\mathrm{E}=\mathrm{Me}_{3} \mathrm{Si}$ or $\mathrm{R}_{3} \mathrm{Sn}$, Eq. (8)). Substituents $\left(\mathrm{R}^{1}, \mathrm{R}^{2}\right)$ in the starting $\mathbf{1 7}$ can vary from hydrogen, alkyl to aryl groups.

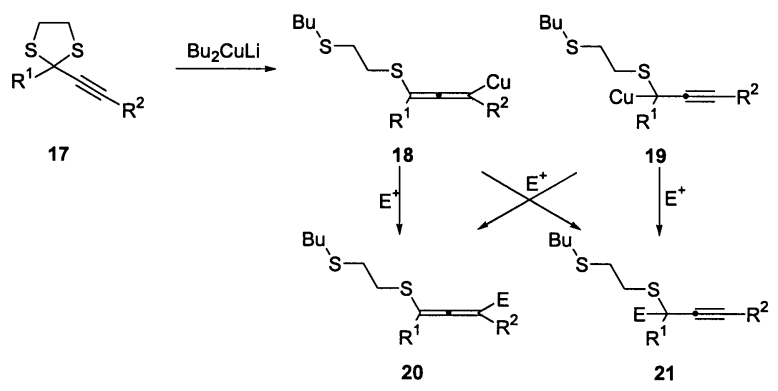

When a soft alkyl halide electrophile is employed, selective carbon-carbon bond formation leading to an excellent yield of propargylic thioether $\mathbf{2 1}$ is observed.

Transmetallation of the organocopper intermediate 18 or 19 with $\mathrm{ZnBr}_{2}$ followed by the palladium-catalyzed coupling reaction gives the corresponding allenes 22 in $65-78 \%$ yield (Eq. (9)).

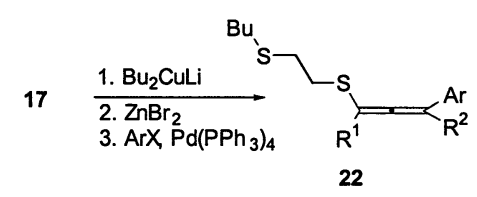

Further reactions of the organosulfur products 20 or 21 with the Grignard reagent in the presence of a nickel catalyst yields the corresponding allenes $\mathbf{2 3}$ or $\mathbf{2 4}$, respectively (Eqs. (10) and (11)) [19]. These results demonstrate the first examples of using propargylic dithioacetals as allene zwitterion synthons $\mathbf{2 5}$.

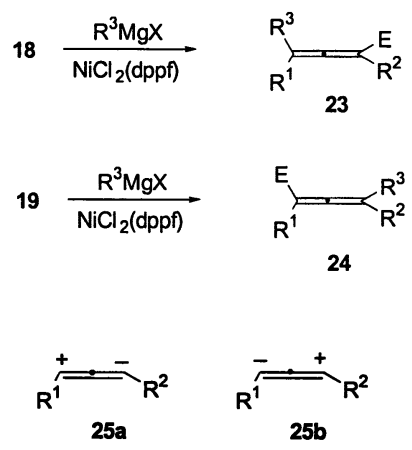

It is known that the propargylic ether can react with an organocopper reagent to yield an $\mathrm{S}_{\mathrm{N}} 2^{\prime}$-like product. It is intriguing to note that treatment of $\mathbf{2 6}$, with $\mathrm{Bu}_{2} \mathrm{CuLi}$, affords the corresponding cumulene 27 in $91 \%$ yield. Apparently, the reactivity of the sulfur moiety in $\mathbf{2 6}$ toward the nucleophile is faster than that of the alkynyl ether group [19]. 


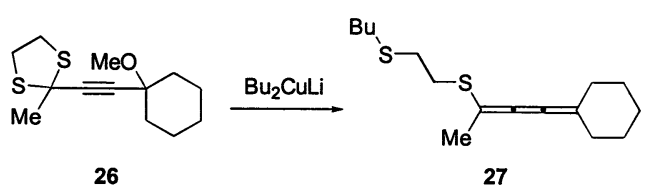

\subsection{Synthesis of furans and pyrroles}

It is well documented that annulation of allenylmethanols and related compounds are known to afford the corresponding five-membered oxygen heterocycles [20]. ${ }^{6-11}$ Thus, treatment of organocopper intermediate 18 or 19 with an aldehyde 28 or an aldimine 29 can afford the intermediate alcohol 30, or amine 31, respectively. Since the thioether moiety in $\mathbf{3 0}$ or $\mathbf{3 1}$ will be a good leaving group, cyclization to eliminate the sulfur moiety will lead to the substituted furan $\mathbf{3 2}$ or pyrrole 33 (Eq. (13)) [21].

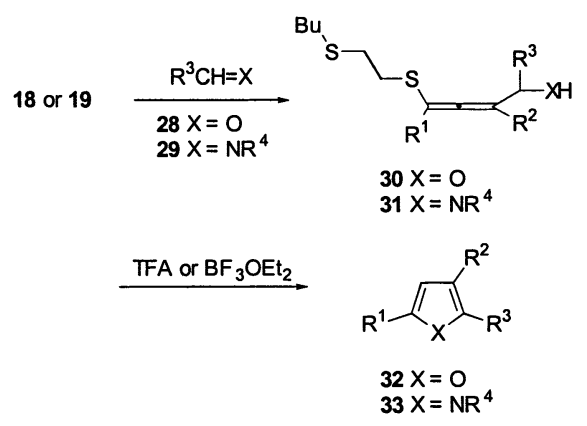

Thus, 17 is allowed to react with $\mathrm{Bu}_{2} \mathrm{CuLi}$ at $-78{ }^{\circ} \mathrm{C}$ followed by treatment with an aldehyde $\mathbf{2 8}$. Trifluoroacetic acid-promoted annulation furnishes the corresponding furans $\mathbf{3 2}$ in satisfactory yield. A range of 2,3,5-trisubstituted furans $\mathbf{3 2}$ can be conveniently synthesized by this procedure. Pyrroles $\mathbf{3 3}$ are also obtained in a similar manner when imines 29 are used as electrophiles. It is noteworthy that $\mathrm{BF}_{3} \cdot \mathrm{OEt}_{2}$ appears to be a better Lewis acid catalyst for the pyrrole synthesis. These reactions are particularly promising to introduce a substituent at $\mathrm{C}_{3}$. It is a common strategy to have such alkyl group to increase the solubility of oligoaryls for the convenience of processing leading to devices for optoelectronic investigations.

Starting from the dialdehydes $\mathbf{3 4}$, oligoaryls $\mathbf{3 6}$ having two furan moieties are obtained in one pot (Eq. (14)). In a similar manner, when a diimine $\mathbf{3 5}$ is employed, bis-pyrroles 37 are prepared (Eq. (14)). A wide range of substituents having different functionalities remains intact under these reaction conditions. Accordingly, further modification of these functionalities may lead to a variety of oligoaryls and the lengths of conjugation can thus be tuned. For example, Heck reaction of 38 with $\mathrm{PhI}$ afforded 39 in $83 \%$ yield (Eq. (15)) [21].

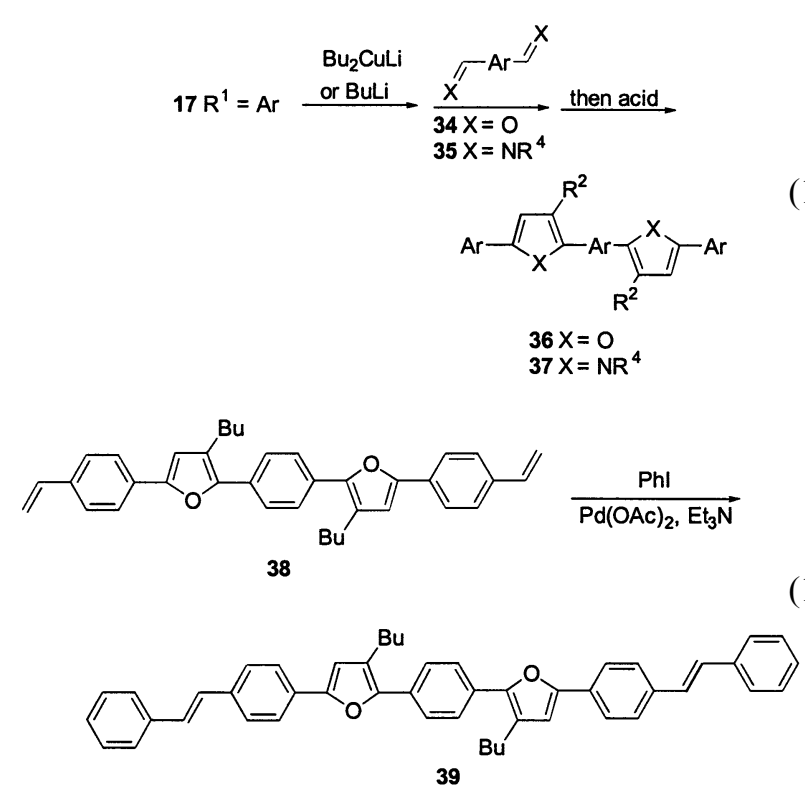

Organic lithium reagents behave similarly. There is no apparent discrepancy in regioselectvities whether organocopper or lithium regent is employed. It is worthy to note that the reactivity of the ditioioacetal moiety under these conditions is faster than that of an ester functionality. Thus, $\mathbf{4 1}$ is prepared from the corresponding dithioacetal $\mathbf{4 0}$ and dialdehyde $\mathbf{3 4}$. Repetitive use of this strategy shown in Eq. (14) has paved the way to the synthesis of a variety of furan or pyrrolecontaining oligoaryls (e.g. 42) [22].

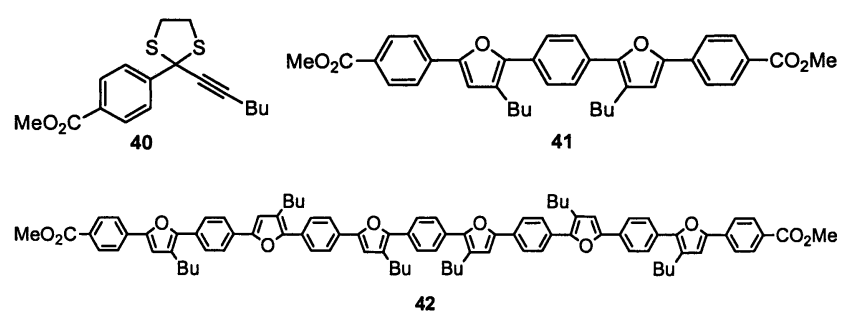

\subsection{Reactions of allylic dithioacetals}

Regioselective replacement of a carbon-heteroatom bond in an unsymmetrical allylic system by a carbon-carbon bond is important in organic synthesis. The selectivity depends on the nature of the substrates, reagents, stoichiometry and reaction conditions [23]. The reaction of allylic dithioacetals 43 with MeMgI in the presence of $\mathrm{NiCl}_{2}$ (dppe) leading to geminal dimethylation product $\mathbf{4 4}$ has been studied in details (Eq. (16)) [24].

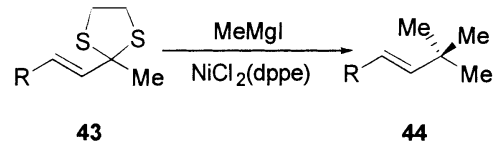

No 1,3-dimethylation product has been observed at all. On the other hand, propargylic dithioacetal 17 can 
serve as an allene 1,3-dication synthon leading to 1,3dimethylation product $\mathbf{4 5}$ under similar conditions (Eq. (17)) [25]. As mentioned earlier, propargylic dithioacetal 17 can behave as an allene 1,3-zwitterion synthon 25 and the regioselectivity of the reaction depends on the nature of the electrophile (Eq. (8)-(11)). Thus, the reaction of $\mathbf{4 6}$ under similar conditions would generate a substituted allylmetallic intermediate 47 which might behave differently from that of the allenyl-propargylic counterpart 18 or 19. Indeed, reaction of 46 with $\mathrm{Bu}_{2} \mathrm{CuLi}$ or $\mathrm{BuLi}$ in THF at $-78{ }^{\circ} \mathrm{C}$ followed by treatment with an alkyl halide affords regioselectively an $E-Z$ mixture of the corresponding vinyl sulfide $\mathbf{4 8}$ in good yield (Eq. (18)). It is interesting to note that the reaction of alkyl electrophile occurs regioselectively at the position away from the sulfur substituent of the corresponding unsymmetrical allyl organometallic species 47. This selectivity is just opposite to that observed for the propargylic substrates [20]. The proton electrophile, however, gives a mixture of regioisomers.

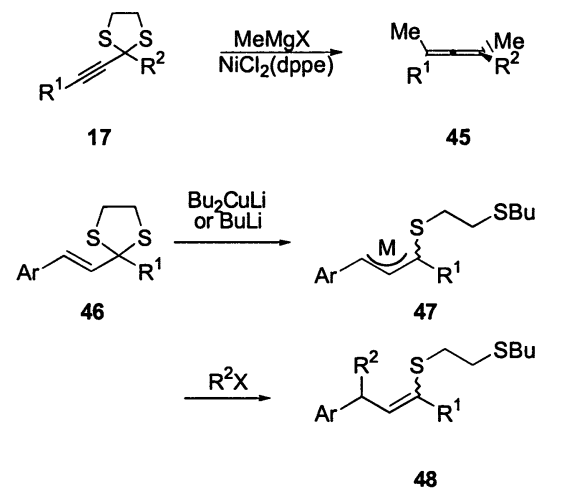

A mixture of $E-Z$ isomeric $\mathbf{4 8}$ is treated with the Grignard reagent in the presence a catalytic amount of $\mathrm{NiCl}_{2}$ (dppe) to afford the corresponding coupling product 49 in good yield (Eq. (19)) [2,26]. In general, the Grignard reagent having the same alkyl group as the $\mathrm{R}^{1}$ group in $\mathbf{4 6}$ is employed so that the stereochemical problem in $\mathbf{4 8}$ can be lifted. The regioselectivity in this reaction just complements that of procedures shown in Eq. (16).

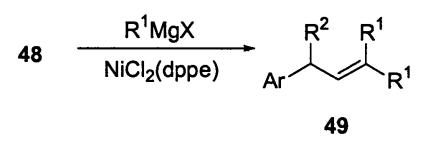

\section{Conclusions}

We have demonstrated the recent advances on the synthetic applications of the dithioacetal functionality. An extension of the olefination reaction has led to the discovery of a new route towards the synthesis of a wide range of conjugated systems for optoelectronic interests. The reaction of propargylic dithioacetals with organolithium or copper reagents furnishes a new entry for the regioselective carbon-carbon bond formation in allene synthesis as well as in five-membered heteroaromatic annulation. In a similar manner, allylic dithioacetal can be considered as a propene 1,3-zwitterion synthon. Due to the rich chemistry of organosulfur compounds, the opportunity for further development involving the dithioacetals abounds.

\section{Acknowledgements}

We thank the National Science Council and Ministry of Education of the Republic of China for support.

\section{References}

[1] F. Diederich, P.J. Stang (Eds.), Metal-Catalyzed Cross-Coupling Reactions, Wiley-VCH, Weinheim, 1998.

[2] (a) H. Okamura, M. Miura, H. Takei, Tetrahedron Lett. (1979) 43

(b) E. Wenkert, T.W. Ferreina, E.L. Michelotti, J. Chem. Soc. Chem. Commun. (1979) 637.

[3] H. Okamura, H. Takei, Tetrahedron Lett. (1979) 3425.

[4] For reviews, see: T.-Y. Luh, Acc. Chem. Res. 24 (1991) 257. Pure Appl. Chem. 68 (1996) 105.

[5] (a) Z.-J. Ni, T.-Y. Luh, J. Org. Chem. 53 (1988) 2129; (b) Z.-J. Ni, P.-F. Yang, D.K.P. Ng, Y.-L. Tzeng, T.-Y. Luh, J. Am. Chem. Soc. 112 (1990) 9356.

[6] (a) D.K.P. Ng, T.-Y. Luh, J. Am. Chem. Soc. 111 (1989) 9119; (b) C.-C. Yu, D.K.P. Ng, B.-L. Chen, T.-Y. Luh, Organometallics 13 (1994) 1487.

[7] H.-R. Tseng, T.-Y. Luh, Organometallics 15 (1996) 3099.

[8] Z.-J. Ni, T.-Y. Luh, J. Chem. Soc., Chem. Commun. (1987) 1515.

[9] H.S. Nalwa (Ed.), Handbook of Organic Conductive Molecules and Polymers, vol. 1-4, Wiley, Chichester, 1997.

[10] (a) S.S. Hu, W.P. Weber, Polym. Bull. 21 (1989) 133; (b) R.J.P. Corriu, C. Guerin, B. Henner, A. Jean, F. Garnier, A. Yassar, T. Kuhlmann, Chem. Mater. 2 (1990) 351;

(c) J. Ohshita, D. Kanaya, M. Ishikawa, T. Koike, T. Yamanaka, Macromolecules 24 (1991) 2106;

(d) H.J. Wu, L.V. Interrante, Macromolecules 25 (1992) 1840;

(e) Y. Pang, S. Ijadi-Maghsoodi, T.J. Barton, Macromolecules 26 (1993) 5671;

(f) C.-H. Yuan, R. West, Appl. Organomet. Chem. 8 (1994) 423; (g) A. Mori, E. Takahisa, H. Kajiro, Y. Nishihara, T. Hiyama, Macromolecules 33 (2000) 1115;

(h) J. Ohshita, A. Takata, H. Kai, A. Kunai, K. Komaguchi, M. Shiotani, A. Adachi, K. Sakamaki, K. Okita, Y. Harima, Y. Kunugi, K. Yamashita, M. Ishikawa, Organometallics 19 (2000) 4492;

(i) H.-K. Kim, M.-K. Ryu, S.-M. Lee, Macromolecules 30 (1997) 1236;

(j) Y.-J. Miao, G.C. Bazan, Macromolecules 30 (1997) 7414.

[11] C.C. Wu, C.W. Chen, Y.T. Lin, H.-L. Yu, J.-H. Hsu, T.-Y. Luh, Appl. Phys. Lett. 79 (2001) 3023.

[12] (a) R.-M. Chen, K.-M. Chien, K.-T. Wong, B.-Y. Jin, T.-Y. Luh, J.-H. Hsu, W. Fann, J. Am. Chem. Soc. 119 (1997) 11321; (b) R.-M. Chen, T.-Y. Luh, Tetrahedron 54 (1998) 1197.

[13] S. Sudhakar, G.-H. Lee, Y. Wang, J.-H. Hsu, T.-Y. Luh, J. Organomet. Chem. in press. 
[14] S. Sudhakar, unpublished results.

[15] R.-M. Chen, Z. Deng, S.T. Lee, T.-Y. Luh, in: B.R. Hsieh, M. Galvin, Y. Wei (Eds.), Semiconductive Polymers, ACS Symposium Series, ACS, Washington DC, 1999 Chapter 23.

[16] Z. Gao, C.S. Lee, I. Bello, S.T. Lee, R.-M. Chen, T.-Y. Luh, J. Shi, C.W. Tang, Appl. Phys. Lett. 74 (1999) 865.

[17] P.G. Gassman, D.P. Gilbert, T.-Y. Luh, J. Org. Chem. 42 (1977) 1340.

[18] (a) A. Krief, B. Kenda, P. Barbeaux, Tetrahedron Lett. 32 (1991) 2509 ;

(b) H. Ikehira, S. Tanimoto, T Oida, J. Chem. Soc., Perkin. Trans. I (1984) 1223.

[19] (a) H.-R. Tseng, T.-Y. Luh, J. Org. Chem. 62 (1997) 4568;

(b) H.-R. Tseng, C.-F. Lee, L.-M. Yang, T.-Y. Luh, J. Org. Chem. 64 (1999) 8582.

[20] (a) J.A. Marshall, X.-J. Wang, J. Org. Chem. 56 (1991) 4913;

(b) J.A. Marshall, C.E. Bennett, J. Org. Chem. 59 (1994) 6110;

(c) S. Kim, Y.G. Kim, Synlett (1991) 869;

(d) D. Obrecht, Helv. Chim. Acta 72 (1989) 447;

(e) N.D. Ly, M. Schlosser, M. Helv. Chim. Acta 60 (1977) 2085;

(f) F.E. McDonald, C.C. Schultz, J. Am. Chem. Soc. 116 (1994) 9363; (g) H.-G. Shu, L.-H. Shiu, S.-H. Wang, S.-L. Wang, G.-H. Lee, S.-M. Peng, R.-S. Liu, J. Am. Chem. Soc. 118 (1996) 530;

(h) N. Iwasawa, K. Maeyama, M. Saitou, J. Am. Chem. Soc. 119 (1997) 1486.

[21] C.-F. Lee, L.-M. Yang, T.-Y. Hwu, A.-S. Feng, J.-C. Tseng, T.-Y. Luh, J. Am. Chem. Soc. 122 (2000) 4992.

[22] Lee, C.-F. unpublished results.

[23] (a) J. Tsuji, Palladium Reagents and Catalysts: Innovations in Organic Synthesis, Wiley, Chichester, 1995, pp. 290-422;

(b) J. Tsuji, Transition Metal Reagents and Catalysis: Innovations in Organic Synthesis, Wiley, Chichester, 2000 Chapters 4 \& 6 ;

(c) Y. Yamamoto, N. Asao, Chem. Rev. 93 (1993) 2207.

[24] (a) P.-F.- Yang, Z.-J. Ni, T.-Y. Luh, J. Org. Chem. 54 (1989) 2261;

(b) Y.-L. Tzeng, P.-F. Yang, N.-W. Mei, T.-M. Yuan, C.-C. Yu, T.-Y. Luh, J. Org. Chem. 56 (1991) 5289;

(c) T.-M. Yuan, T.-Y. Luh, J. Org. Chem. 57 (1992) 4550;

(d) T.-M. Yuan, T.-Y. Luh, Org. Syn. 74 (1996) 187.

[25] H.-R. Tseng, T.-Y. Luh, J. Org. Chem. 61 (1996) 8685.

[26] C.-C. Chiang, T.-Y. Luh, Synlett (2001) 977. 